\title{
The evolution of internal stress and dislocation during tensile deformation in a 9Cr Ferritic/Martensitic (F/M) ODS steel investigated by high-energy $\mathrm{X}$-rays
}

\author{
Guangming Zhang ${ }^{\mathrm{a}, \mathrm{b}}$, Zhangjian Zhou ${ }^{\mathrm{a}, *}$, Kun $\mathrm{Mo}^{\mathrm{c}}$, Yinbin Miao ${ }^{\mathrm{b}}$, Xiang Liu ${ }^{\mathrm{b}}$, Jonathan Almer ${ }^{\mathrm{d}}$, \\ James F. Stubbins ${ }^{b}$ \\ ${ }^{a}$ School of Materials Science and Engineering, University of Science and Technology, Beijing, \\ Beijing 100083, China \\ ${ }^{b}$ Department of Nuclear, Plasma and Radiological Engineering, University of Illinois at \\ Urbana-Champaign, IL 61801,USA \\ ${ }^{c}$ Nuclear Engineering Division, Argonne National Laboratory, Argonne, IL 60439, USA \\ ${ }^{d} X$-ray Science Division, Argonne National Laboratory, Argonne, IL 60439, USA \\ *Corresponding author Telephone: +86 10 62332472; Fax: +86 1062332472 ;
}

Email address: zhouzhj@mater.ustb.edu.cn (Zhangjian Zhou) 
Abstract: An application of high-energy wide angle synchrotron X-ray diffraction to investigate the tensile deformation of $9 \mathrm{Cr}$ ferritic/martensitic (F/M) ODS steel is presented. With tensile loading and in-situ X-ray exposure, the lattice strain development of matrix was determined. The lattice strain was found to decrease with increasing temperature, and the difference in Young's modulus of six different reflections at different temperatures reveals the temperature dependence of elastic anisotropy. The mean internal stress was calculated and compared with the applied stress, showing that the strengthening factor increased with increasing temperature, indicating that the oxide nanoparticles have a good strengthening impact at high temperature. The dislocation density and character were also measured during tensile deformation. The dislocation density decreased with increasing of temperature due to the greater mobility of dislocation at high temperature. The dislocation character was determined by best-fit methods for different dislocation average contrasts with various levels of uncertainty. The results shows edge type dislocations dominate the plastic strain at room temperature (RT) and $300{ }^{\circ} \mathrm{C}$, while the screw type dislocations dominate at $600{ }^{\circ} \mathrm{C}$. The dominance of edge character in $9 \mathrm{Cr}$ F/M ODS steels at RT and $300{ }^{\circ} \mathrm{C}$ is likely due to the pinning effect of nanoparticles for higher mobile edge dislocations when compared with screw dislocations, while the stronger screw type of dislocation structure at $600{ }^{\circ} \mathrm{C}$ maybe explained by the activated cross slip of screw segments.

Keywords: synchrotron XRD; mean internal stress; dislocation character; dislocation density

\section{Introduction}

Oxide dispersion strengthened (ODS) ferritic /martensitic steels are considered to be promising candidates for the breeding blanket material in a fusion reactor and fuel cladding tubes in Gen IV fission reactors [1, 2, 3]. The well-distributed nanoscale particles within the steels are critical to their excellent irradiation resistance, high-temperature strength, and superb creep properties $[4,5,6]$. These nanoscale particles are effective obstacles for dislocation movement which provide additional strengthening of the F/M matrix especially at high temperature, when compared with reduced activation Ferritic/Martensitic (RAFM) steels, such as Eurofer 97, F82H and ORNL 9Cr2WTaV [7, 8].

Dislocations are important microstructure features, as their mobility greatly impacts the strength and plasticity of crystal materials. A knowledge of the dislocation density, dislocation character, and the interaction 
between dislocations and dispersed particles during plastic deformation in a material is essential not only from a fundamental perspective, but also for engineering applications. The dislocation density can be measured by direct methods such as transmission electron microscope (TEM) and indirect methods such as X-ray diffraction (XRD). X-ray line profile analysis is a proven technique for studying the dislocation density in deformed metals $[9,10]$. In addition, the modified Williamson-Hall (W-H) plot and the modified Warren-Averbach analysis have been applied to calculate dislocation density, twin-boundaries, and stacking-faults [11]. The W-H plot has also been applied to investigate the dislocation densities of $80 \%$ cold-rolled ODS-Eurofer steel annealed at different temperatures in ref. [12]. Some works have been done using the X-ray Bragg profile to determine the dislocation character (edge type and screw type) $[13,14,15]$. However the evolution of the dislocation character during the entirety of plastic deformation in ODS steel is still far from complete, especially the behaviour at high temperature.

In this study, an in-situ high-energy synchrotron radiation X-ray was used to monitor the microstructural evolution throughout the tensile deformation processes of a 9Cr F/M ODS steel from room temperature (RT) to $600{ }^{\circ} \mathrm{C}$. The mean internal stress, dislocation density, and dislocation character were investigated. The dislocation density was also measured by using transmission electron microscope (TEM) at RT, $300{ }^{\circ} \mathrm{C}$ and $600^{\circ} \mathrm{C}$.

\section{Experimental Procedure}

9Cr F/M ODS steel with a nominal composition of Fe-9Cr-0.06C-1.5W-0.18Si-0.5Ti-0.35 $\mathrm{Y}_{2} \mathrm{O}_{3}$ was fabricated by mechanical alloying (MA), hot isostatic pressing (HIP), and hot working (hot forging and hot rolling) $[16,17]$. Then, the $9 \mathrm{Cr}$ F/M ODS steel was cut into tensile specimens by electrical discharge machining $(E D M)$ with a gauge section of $1.49 \mathrm{~mm} \times 0.76 \mathrm{~mm} \times 7.60 \mathrm{~mm}$. The in-situ synchrotron tensile tests were conducted at the 1-ID beamline at the Advanced Photon Source (APS) at Argonne National Laboratory (ANL), as illustrated in Figure 1. The tensile test with a strain rate of $10^{-4} \mathrm{~s}^{-1}$ was held at each stress/strain state to allow X-ray diffraction scanning along the gauge part of the tensile specimen in order to catch its necking area using an MTS closed-loop servo-hydraulic test frame (model 858) [18, 19]. Experimental temperature conditions from RT up to $600{ }^{\circ} \mathrm{C}$ were examined. The diffraction analysis was performed by using a monochromatic $70 \mathrm{keV}$ synchrotron beam with a $300 \mu \mathrm{m} \times 300 \mu \mathrm{m}$ cross-section. The 
sample to detector distance was set as $2082.5 \mathrm{~mm}$. The 'Hydra' detector array containing four identical GE angio type $2 \mathrm{D}$ detectors with a pixel size of 0.2 was utilized to collect the wide angle diffraction information. The $15^{\circ}$ region of the Debye-Scherrer rings near the tensile direction was integrated to obtain the lattice strain of the matrix, $\varepsilon_{11}=\left(d-d_{0}\right) / d_{0}$, peak broadening and peak intensity. The TEM samples were lifted out from the gauge part of the tensile specimen near the fracture surface by an FEI HELIOS 600i FIB. Diffraction contrast images were used to characterize the dislocation density after tensile deformation. All TEM images were taken on a JEOL $2010 \mathrm{LaB}_{6}$ TEM.

\section{Results and discussion}

\subsection{Macro-mechanical properties}

Figure 2 shows the engineering stress-engineering strain curves for the 9Cr F/M ODS steel tested at RT, $300{ }^{\circ} \mathrm{C}, 500{ }^{\circ} \mathrm{C}$, and $600{ }^{\circ} \mathrm{C}$. The material's yield strengths (YS) are $845 \mathrm{MPa}, 665 \mathrm{MPa}, 343 \mathrm{MPa}$ and $216 \mathrm{MPa}$, respectively, and ultimate tensile strengths (UTS) are $915 \mathrm{MPa}, 760 \mathrm{MPa}, 432 \mathrm{MPa}$ and $268 \mathrm{MPa}$, respectively. The UTS dropped from $915 \mathrm{MPa}$ to $268 \mathrm{MPa}$ from RT to $600{ }^{\circ} \mathrm{C}$, while the total elongation dropped from 0.16 at RT to 0.122 at $500{ }^{\circ} \mathrm{C}$, and then increased to 0.245 at $600{ }^{\circ} \mathrm{C}$, which agrees well with the results of the ODS EUROFER97 alloy reported in ref. [20]. Although the tensile tests were stopped periodically in order to capture the necking area, the stress-strain curves were smooth with the exception of the curve of $300{ }^{\circ} \mathrm{C}$. The serrated points at $300{ }^{\circ} \mathrm{C}$ may be ascribed to dynamic strain aging (DSA) according results from Mariappan et al. stating DSA occurred at intermediate temperature around $650 \mathrm{~K}$ in a reduced activation ferritic/martensitic (RAFM) steel [21]. The serrations were accompanied by an increase in work-hardening and a loss of ductility.

Figure 3 shows the true stress-lattice strain curves for six different $\langle\mathrm{hkl}\rangle / /$ tensile direction families of grains. The lattice strains of six reflections are hook-shaped at RT, while those of $600{ }^{\circ} \mathrm{C}$ are not visible. The hook-shaped region corresponds to the period that matrix phase starts to transfer load to the precipitate phases. This phenomenon indicates that the load partitioning between matrix and nanosclae particles became weaker with increasing temperature [22]. The lattice strains of six reflections increase with the increasing of stress, and decrease with increasing temperature. The lattice strain at RT is almost twice that at $600{ }^{\circ} \mathrm{C}$ for each lattice plane. Young's modulus E is the slope calculated by assuming a linear fit between stress and strain in the elastic regime, as shown in Table 1. At two different temperatures, the (200) plane was the softest plane of all 
six planes, while the (321) reflection remained at intermediate range at RT, and became the hardest plane at $600{ }^{\circ} \mathrm{C}$, indicating that elastic anisotropy of lattice planes behave individually with temperature. This temperature dependence has been discussed in 14YWT by Stoica et al.[23]. The larger difference of E among six reflections at $600{ }^{\circ} \mathrm{C}$ than that at $\mathrm{RT}$ reveals the increasing anisotropy with increasing temperature. In previous works $[24,25,26]$, the lattice strain of the specific reflection (211) was selected to represent the lattice strain of the Fe-Cr matrix, but the texture index [27] should be considered due to the temperature dependence of elastic anisotropy.

\subsection{Mean internal stress vs. true stress}

In order to investigate the strengthening effect of nanoscale particles, i.e. the strength increase in ODS steel compared with the strength of non-ODS steel. The mean internal stress of the matrix was calculated for comparison with the applied stress loaded by the tensile machine. The mean internal stress relies on the mean lattice strain of matrix, which was calculated from the lattice strains of (110), (200), (211), (310), (321) and (411) reflections using the weighted averaging algorithm developed by Daymond [28]. This method has been used to calculate the mean lattice strain for the matrix of Zircaloy-2 by averaging five Zircaloy-2 peaks [29, 30]. First, the texture index $T$ as one of the necessary parameters for this method was calculated. The texture index $T$ of the reflection $h_{i}=h_{i} k_{i} l_{i}$ is defined by the following equations:

$$
T\left(h_{i}\right)=\frac{I\left(h_{i}\right) / R\left(h_{i}\right)}{\frac{1}{n} \sum_{j=1}^{n} I\left(h_{j}\right) / R\left(h_{j}\right)}
$$

, where $I\left(h_{j}\right)$ is the integrated intensity of reflection $h_{j}$, and $R\left(h_{j}\right)$ is the integrated intensity calculated from the structure factor and other parameters for a sample with a random orientation of crystallites, which has the following expression:

$$
R_{h k l}=\frac{1}{V}\left[|F|^{2} p\left(\frac{1+\cos ^{2} 2 \theta}{\sin ^{2} 2 \theta \cos \theta}\right)\right] e^{-2 M}
$$

where $V$ is the volume of the unit cell; $F$ is the structure factor; $p$ is the multiplicity of the reflection; $\frac{1+\cos ^{2} 2 \theta}{\sin ^{2} 2 \theta \cos \theta}$ is the Lorentz-polorization factor as a function of diffraction angle $\theta$; and $e^{-2 M}$ is the temperature factor, which was calculated according to the Debye temperature and experimental temperature. Thus, the mean internal stress $\bar{\sigma}$ was defined as equation 3 .

$$
\bar{\sigma}=\bar{E} \frac{\sum_{h k l} T_{h k l}(\Phi, \Psi) m_{h k l} E_{h k l} \varepsilon_{h k l}}{\sum_{h k l} T_{h k l}(\Phi, \Psi) m_{h k l} E_{h k l}}
$$


where, $\bar{E}$ is the average Young's modulus of the bulk matrix, values which were taken from [31] for F82H (given in Table 2) due to its similarity to the bulk matrix of 9Cr ODS; and $m$ is the multiplicity of the reflection. Thus, the mean internal stress and true stress are shown in Figure 4. It can be seen that the difference begins after yielding, and reaches a peak at the onset of necking. As is known, the exceptional mechanical properties of ODS steels are ascribed to the dispersed nanoscale particles and the fine grains according to the Orowan strengthening and Hall-Petch strengthening. The difference between applied stress and the mean internal stress was mainly induced by the Orowan strengthening. Then, the difference between the internal stress of matrix and the true stress at the necking point were used to analyze the strengthening effect of nanosacle particles. A given strengthening factor $(S F)$ was defined as the percentage increase of strength of ODS steel comparing with matrix of ODS steel, which is shown in equation 4 ,

$$
\mathrm{SF}=\frac{\sigma_{\text {Applied }}-\sigma_{\text {Matrix }}}{\sigma_{\text {Matrix }}}
$$

Where, the $S F$ was calculated using the applied stress $\sigma_{\text {Applied }}$ and the mean internal stress $\sigma_{\text {Matrix }}$ at necking point in Figure 5. This shows that the $S F$ has a strong temperature dependence, which increases with increasing temperature from RT to $600{ }^{\circ} \mathrm{C}$. However, the unexpected results of the SF at $300{ }^{\circ} \mathrm{C}$ being much higher than that at $500{ }^{\circ} \mathrm{C}$, may be ascribed DSA. The solution atoms diffuse around dislocations, further strengthening the obstacles, which may provide an additional strengthening effect at $300{ }^{\circ} \mathrm{C}$. Though the load partitioning became weaker with increasing temperature due to the higher mobility of dislocations, the increasing SF with increasing temperature indicates the increasing percentage of stress strengthened by nanoscale particles. Therefore, the nanoscale particles plays a more important role for strengthening at high temperatures comparing with other strengthening mechanisms.

\subsection{Dislocation evolution}

The full width at half-maximum (FWHM) of Fe-Cr matrix peaks were measured during the process of tensile deformation at RT, $300{ }^{\circ} \mathrm{C}, 500{ }^{\circ} \mathrm{C}$, and $600{ }^{\circ} \mathrm{C}$. The $\mathrm{CeO}_{2}$ sample was used as the reference material for obtaining instrumental broadening profile. The FWHM of Fe-Cr matrix was calibrated corresponding to instrumental broadening profile using the relation as follows:

$$
\mathrm{FWHM}=\left[\left(F W H M_{\text {measured }}\right)^{2}-\left(F W H M_{\text {instrumental }}\right)^{2}\right]^{\frac{1}{2}}
$$

Figure 6 shows the FWHM evolutions of eight bcc Fe-Cr peaks of (200), (211), (220), (310), (222), (321), 
(400) and (330) during tensile straining in the 9Cr F/M ODS steel at RT and $600{ }^{\circ} \mathrm{C}$ respectively. The FWHM of all $\mathrm{Fe}-\mathrm{Cr}$ peaks increased with the increasing strain during the macroscopic deformation. As mentioned in [32], the FWHM Fe(400) > the FWHM Fe(330) and FWHM Fe(310) > the FWHM Fe(222) indicates anisotropic strain broadening. The relationship between the FWHM of the eight peaks also changes with temperature, since FWHM Fe(222) > the FWHM Fe(211) at RT while FWHM Fe(222) < FWHM Fe(211) at $600{ }^{\circ} \mathrm{C}$. This indicates a temperature dependence of the anisotropic strain broadening. The modified W-H plot was applied to calculate the dislocation density by the following equation:

$$
\Delta \mathrm{K}=\frac{0.9}{D}+\left(\frac{\pi M^{2} b^{2}}{2}\right)^{\frac{1}{2}} \rho^{\frac{1}{2}}\left(\mathrm{~K} C^{\frac{1}{2}}\right)
$$

Where $K=2 \sin \theta / \lambda ; \Delta K=2 \cos \theta \Delta \theta / \lambda ; \theta$ is the diffraction angle, and $\Delta \theta$ is half of the FWHM of the diffraction peak; $D$ is the average grain size; $M$ is an adjustable parameter, which should be fitted together with the rest of the parameters of the model. In this experimental, $M=2$ was used for all samples to give the level of accuracy expected by the $\mathrm{W}-\mathrm{H}$ approach [12]. $b$ is the Burgers vector of dislocations and $\rho$ is dislocation density; and $C$ is the dislocation contrast factor which depends on different possible combinations of Burgers vectors, line vectors of dislocations, the diffraction vector and anisotropic elastic constants [33]. The dislocation contrast factors $C$ for pure edge and pure screw dislocations at different temperatures were calculated which have concerned anisotropic elastic constants caused by temperature.

Shintani et al. obtained $q$ from the coefficients of $H^{2}$ in the linear function and compared the measured and theoretical $q$ values of pure edge type and pure screw type dislocations to determine the fraction of each [13]. Figure 7 shows the $\mathrm{W}-\mathrm{H}$ plots at two plastic strain levels $(0,3.4 \%)$ at RT by using the dislocation contrast factor of pure edge type, dislocation contrast of pure screw type and best-fit method, respectively.

In each plot, a least-square fitting line is drawn with a $R^{2}$ coefficient. It can be seen that the $R^{2}$ coefficient changed with increasing strain. At a plastic strain of $0 \%$, the dislocation contrast factor of screw type dislocations exhibited a better linear fit $\left(R^{2}=0.944\right)$ than that of edge type dislocations, while the dislocation contrast factor of edge type dislocations exhibited a better linear fit $\left(R^{2}=0.963\right)$ at a plastic strain of $4.3 \%$. Li et al. [34] investigated the dislocation character by selecting a best fit from the modified W-H plot using five different corresponding dislocation contrast factors according to different ratios of pure edge and pure screw dislocations. Schafler et al. [14] have proven that the specific fraction of each dislocation type can be determined by comparing experimental and theoretical $C$-values. In order to obtain in-situ results of dislocation 
character, this method was refined such that the dislocation average contrast factor was divided into 100 steps from $100 \%$ edge type with $0 \%$ screw type to $0 \%$ edge type with $100 \%$ screw type, one couple of examples were shown in Figure 7(c). Then the best-fit result was selected to calculate the dislocation density and determine the dislocation character during process of tensile deformation at $\mathrm{RT}, 300{ }^{\circ} \mathrm{C}, 500{ }^{\circ} \mathrm{C}$ and $600{ }^{\circ} \mathrm{C}$.

Figure 8 shows the evolution of dislocation densities with plastic deformation at RT, $300{ }^{\circ} \mathrm{C}, 500{ }^{\circ} \mathrm{C}$, and $600{ }^{\circ} \mathrm{C}$. Although the results of dislocation density obtained by the evaluation method are only semi-quantitative, the results still can be used to investigate the influence of deformation and temperature on the dislocation density and characters. It can be seen that the dislocation density increased quickly to a maximum in the very beginning region and then remains stable with increasing plastic strain at these four temperatures. The maximum dislocation density at the four tested temperatures is about $(6.05 \pm 0.37) \times 10^{14} \mathrm{~m}^{-2}$ (RT), $(5.13 \pm 0.45) \times 10^{14} \mathrm{~m}^{-2}\left(300{ }^{\circ} \mathrm{C}\right),(2.91 \pm 0.27) \times 10^{14} \mathrm{~m}^{-2}\left(600{ }^{\circ} \mathrm{C}\right)$, respectively. The increase speed of dislocation density decreased with increasing temperature due to the higher mobility of dislocations at high temperature. The dislocation density also decreased with increasing temperature with an exception at $300{ }^{\circ} \mathrm{C}$. As mentioned in the description of macro-mechanical properties of $9 \mathrm{Cr}$ F/M ODS steel, DSA occurs at $300^{\circ} \mathrm{C}$. The solution atoms diffuse around dislocations further strengthening the obstacles. Thus, the dislocation density at $300^{\circ} \mathrm{C}$ is slightly higher than that at RT.

Figure 9 shows the density evolution of edge type and screw type dislocations during plastic deformation at RT, $300{ }^{\circ} \mathrm{C}$ and $600{ }^{\circ} \mathrm{C}$. In general, the dislocation structure changes with increasing plastic strain and increasing temperature. At RT and $300{ }^{\circ} \mathrm{C}$, the dislocation density of edge type dislocations is much higher than that of screw type dislocations, while the screw dislocation density is much higher than the edge dislocation density at $600{ }^{\circ} \mathrm{C}$. The edge type dislocations dominate the plastic deformation at RT and $300{ }^{\circ} \mathrm{C}$, while the proportion of edge type dislocations decreased with increasing temperature. As temperature increased up to $600{ }^{\circ} \mathrm{C}$, the screw type dislocations began to dominate the plastic deformation. The temperature dependence of dislocation character during plastic deformation is an interesting issue, and may play an important role in the strengthening mechanisms in ODS steel. The edge type dislocations are assumed to play a minor role in the hardening of bcc metals due to their higher mobility compared with screw dislocations [35], and because the Orowan stress for edge dislocations is known to be much smaller than that for screw dislocations in MA956 [36]. Therefore, the edge dislocations bypasses nanoparticles more easily than screw dislocation at low 
temperature (RT and $300{ }^{\circ} \mathrm{C}$ ), which results in the stronger edge character [33]. At elevated temperature (600 $\mathrm{oC}$ ), although the Orowan stress of screw dislocations is still larger than that of edge dislocations, the slip of screw dislocation can occur on $\{110\},\{112\}$, and $\{123\}$ planes including cross slip between these planes, which encourages the dominance of screw dislocations at $600{ }^{\circ} \mathrm{C}$.

\subsection{Dislocation densities of post-tensile specimens measured by TEM}

TEM micrographs of post-tensile specimens near the fracture region at RT, $300{ }^{\circ} \mathrm{C}$, and $600{ }^{\circ} \mathrm{C}$ are shown in Figure 10. The bright field TEM images were taken at around $3 g$ conditions of either $\{110\}$ or $\{200\}$ reflections to provide the dislocation density information. Three images were used to measure the dislocation density for each condition. And the uncertainties were estimated by using the error of linear fitting, which is based on linear regression techniques. The high dislocation density and multiple sub-grains can be seen in the grains of specimen tested at RT. As the temperature increased to $600{ }^{\circ} \mathrm{C}$, the sub-grains disappeared and the dislocation density decreased from $(6.6 \pm 2.4) \times 10^{14} \mathrm{~m}^{-2}$ at RT to $(5.4 \pm 1.7) \times 10^{14} \mathrm{~m}^{-2}$ at $300^{\circ} \mathrm{C}$ to $(3.5 \pm 1.3) \times$ $10^{14} \mathrm{~m}^{-2}$ at $600{ }^{\circ} \mathrm{C}$, matching with the maximum dislocation density of $(6.05 \pm 0.37) \times 10^{14} \mathrm{~m}^{-2}$ at $\mathrm{RT},(5.13 \pm 0.45)$ $\times 10^{14} \mathrm{~m}^{-2}$ at $300{ }^{\circ} \mathrm{C}$, and $(2.91 \pm 0.27) \times 10^{14} \mathrm{~m}^{-2}$ at $600{ }^{\circ} \mathrm{C}$ respectively as calculated from the X-ray profile line.

\section{Conclusions}

A high-energy wide angle synchrotron X-ray diffraction technique was applied to study the tensile deformation of a 9Cr F/M ODS steel. The lattice strain of six planes decreased with the increasing tensile test temperature, and the elastic anisotropy revealed the important temperature dependence. The mean internal stress was calculated and compared with the applied stress. The strengthening factor increased with the increasing temperature, indicating that oxide nanoscale particles provide an enhanced strengthening role at high temperatures. The dislocation density and character were also measured by the modified W-H plot during tensile deformation. The dislocation density decreased with increasing temperature due to the greater mobility of dislocations at high temperature. The TEM observation of post-tensile specimens confirmed the dislocation density change. The dislocation character was determined by a best-fit method for different dislocation average 
contrasts with various levels of uncertainty. The results show that edge type dislocations dominate the plastic strain at RT and $300{ }^{\circ} \mathrm{C}$, while the screw type dislocations dominate at $600{ }^{\circ} \mathrm{C}$. The stronger edge character in 9Cr F/M ODS steel at RT and $300{ }^{\circ} \mathrm{C}$ is likely due to the pinning effect of nanoparticles for higher mobile edge dislocation when compared with screw dislocation, while the stronger screw type of dislocation structure at $600{ }^{\circ} \mathrm{C}$ maybe explained by activated cross slip of screw segments.

\section{Acknowledgements}

This work was supported by 973 DOE INL 120293. The TEM experiments were carried out in part in the Frederick Seitz Materials Research Laboratory Central Facilities, University of Illinois, which is partially supported by the U.S. Department of Energy under grants DEFG02-07ER46453 and DE-FG02-07ER46471. Argonne National Laboratory's work was supported by U.S. DOE under Contract No. DE-AC02-06CH11357. The authors also would like to express their thanks for the financial support of the National Magnetic Confinement Fusion Program of China under Grant No. 2015GB121006 for samples preparation.

\section{References}

[1] G.R. Odette, M.J. Alinger, B.D. Wirth, Annu. Rev. Mater. Res., 38 (2008) 471-503.

[2] R. Lindau, A. Möslang, M. Schirra, P. Schlossmacher, M. Klimenkov, Journal of Nuclear Materials, 307 (2002) 769-772.

[3] M. Klimenkov, R. Lindau, A. Möslang, Journal of Nuclear Materials, 386 (2009) 553-556.

[4] S. Ukai, T. Okuda, M. Fujiwara, T. Kobayashi, S. Mizuta, H. Nakashima, Journal of nuclear science and technology, 39 (2002) 872-879.

[5] T.K. Kim, C.S. Bae, D. Kim, J. Jang, S.H. Kim, C.B. Lee, D. Hahn, Nuclear Engineering and Technology, $40(2008) 305$.

[6] S. Yamashita, N. Akasaka, S. Ukai, S. Ohnuki, Journal of Nuclear Materials, 367 (2007) 202-207.

[7] R. Lindau, A.M. Möslang, M. Rieth, M. Klimiankou, E. Materna-Morris, A. Alamo, A.-A. Tavassoli, C. Cayron, A.-M. Lancha, P. Fernandez, Fusion Engineering and Design, 75 (2005) 989-996.

[8] S. Jitsukawa, A. Kimura, A. Kohyama, R. Klueh, A. Tavassoli, B. Van der Schaaf, G. Odette, J. Rensman, M. Victoria, C. Petersen, Journal of Nuclear Materials, 329 (2004) 39-46. 
[9] H.-A. Kuhn, H. Biermann, T. Ungar, H. Mughrabi, Acta metallurgica et materialia, 39 (1991) 2783-2794.

[10] T. Ungár, H. Mughrabi, D. Rönnpagel, M. Wilkens, Acta Metallurgica, 32 (1984) 333-342.

[11] T. Ungár, in: Materials Science Forum, volume 278, Trans Tech Publ, pp. 151-157.

[12] R. Renzetti, H. Sandim, R. Bolmaro, P. Suzuki, A. Möslang, Materials Science and Engineering: A, 534 (2012) 142-146.

[13] T. Shintani, Y. Murata, Acta Materialia, 59 (2011) 4314-4322.

[14] E. Schafler, M. Zehetbauer, T. Ungar, Materials Science and Engineering: A, 319 (2001) 220-223.

[15] T. Ungár, in: Investigations and Applications of Severe Plastic Deformation, Springer, 2000, pp. 93-102.

[16] G. Zhang, Z. Zhou, H. Sun, L. Zou, M. Wang, S. Li, Journal of Nuclear Materials, 455 (2014) 139-144.

[17] G. Zhang, Z. Zhou, M. Wang, S. Li, L. Zou, L. Zhang, Fusion Engineering and Design, 89 (2014) $280-283$

[18] K.-D. Liss, K. Yan, Materials science and engineering: A, 528 (2010) 11-27.

[19] D. Qu, K.-D. Liss, Y. Sun, M. Reid, J. Almer, K. Yan, Y. Wang, X. Liao, J. Shen, Acta Materialia, 61 (2013) 321-330.

[20] A. Ramar, P. Spätig, R. Schäublin, Journal of Nuclear Materials, 382 (2008) 210-216.

[21] K. Mariappan, V. Shankar, R. Sandhya, G. Prasad Reddy, M. Mathew, Journal of Nuclear Materials, 435 (2013) 207-213.

[22] G. Zhang, K. Mo, Y. Miao, X. Liu, J. Almer, Z. Zhou, J. F. stubbins, Materials Science and Engineering: A, 637 (2015) 75-81.

[23] G.M. Stoica, A.D. Stoica, M.K. Miller, D. Ma, Nature communications, 5 (2014).

[24] K. Mo, Z. Zhou, Y. Miao, D. Yun, H.-M. Tung, G. Zhang, W. Chen, J. Almer, J.F. Stubbins, Journal of NuclearMaterials, 455 (2014) 376-381.

[25] X. Pan, X. Wu, K. Mo, X. Chen, J. Almer, J. Ilavsky, D.R. Haeffner, J.F. Stubbins, Journal of Nuclear Materials, 407 (2010) 10-15.

[26] M. Young, J. DeFouw, J. Almer, D. Dunand, Acta materialia 55 (2007) 3467-3478.

[27] G. Harris, Philosophical Magazine 43 (1952) 113-123.

[28] M.R. Daymond, Journal of applied physics, 96 (2004) 4263-4272.

[29] M. Kerr, M.R. Daymond, R.A. Holt, J.D. Almer, Journal of Nuclear Materials, 380 (2008) 70-75. 
[30] F. Xu, R.A. Holt, M.R. Daymond, R.B. Rogge, E.C. Oliver. Materials Science and Engineering: A, 488 (2008) 172-185.

[31] S. Zinkle, J. Robertson, R. Klueh, Thermophysical and Mechanical Properties of Fe-(8-9)\% Cr reduced activationsteels, Technical Report, Oak Ridge National Lab., TN (United States), 1998.

[32] L. Wang, M. Li, J. Almer, Journal of Nuclear Materials, 440 (2013) 81-90.

[33] T. Ungár, I. Dragomir, Á. Révész, A. Borbély, Journal of applied crystallography, 32 (1999) 992-1002.

[34] M. Li, L. Wang, J. D. Almer, Acta Materialia, 76 (2014) 381-393.

[35] S. Queyreau, J. Marian, M. Gilbert, B. Wirth, Physical Review B, 84 (2011) 064106.

[36] M. Bartsch, A. Wasilkowska, A. Czyrska-Filemonowicz, U. Messerschmidt, Materials Science and Engineering: A, 272 (1999) 152-162.

\section{Figure captions}

Figure 1: Experimental set-up of the tensile test with in-situ synchrotron X-ray diffraction.

Figure 2: Engineering stress vs. engineering strain from RT to $600{ }^{\circ} \mathrm{C}$.

Figure 3: The true stress vs. lattice strain for six different $<\mathrm{hkl}>/ /$ tensile direction families of grains for $9 \mathrm{Cr}$ F/M ODS steel at (a) RT; and (b) $600{ }^{\circ} \mathrm{C}$.

Figure 4: The true stress and mean internal stress of 9Cr F/M ODS steel during tensile test at RT, $300{ }^{\circ} \mathrm{C}, 500$ ${ }^{\circ} \mathrm{C}, 600{ }^{\circ} \mathrm{C}$.

Figure 5: The strengthening factor of 9Cr F/M ODS steel

Figure 6: Evolution of the FWHM of the Fe-Cr matrix as a function of strain during tensile deformation for 9Cr F/M ODS steel at (a) RT; and (b) $600{ }^{\circ} \mathrm{C}$.

Figure 7: The modified Williamson-Hall plots for Fe-Cr peaks at different strains at RT using the dislocation contrast factor of (a) pure edge type dislocations; (b) pure screw type dislocations; and (c) best-fit method.

Figure 8: The evolution of dislocation density as a function of plastic strain for 9Cr F/M ODS steel at RT, 300 ${ }^{\circ} \mathrm{C}$, and $600{ }^{\circ} \mathrm{C}$.

Figure 9: The density evolution of edge type and screw type dislocations with increasing plastic strain of $9 \mathrm{Cr}$ F/M ODS steel at (a) RT; (b) $300^{\circ} \mathrm{C}$; and (c) $600^{\circ} \mathrm{C}$.

Figure 10: The bright field of TEM images of post-tensile testing specimens of 9Cr F/M ODS steel at (a) RT; 
(b) $300{ }^{\circ} \mathrm{C}$; and (c) $600{ }^{\circ} \mathrm{C}$.

\section{Table captions}

Table 1: Young's modulus of the Fe-Cr matrix at six different reflections for 9Cr F/M ODS steel

Table 2: The Young's modulus of F82H from RT to $600{ }^{\circ} \mathrm{C}$ 
Table 1 Young's modulus of the Fe-Cr matrix at six different reflections for 9Cr F/M ODS steel.

\begin{tabular}{ccccccc}
\hline Young's modulus E (GPa) & $(110)$ & $(200)$ & $(211)$ & $(310)$ & $(321)$ & $(411)$ \\
\hline $\mathrm{RT}$ & $213 \pm 2$ & $175 \pm 2$ & $204 \pm 3$ & $191 \pm 1$ & $211 \pm 3$ & $212 \pm 1$ \\
$300{ }^{\circ} \mathrm{C}$ & $201 \pm 5$ & $158 \pm 4$ & $196 \pm 5$ & $176 \pm 4$ & $191 \pm 5$ & $193 \pm 5$ \\
$500{ }^{\circ} \mathrm{C}$ & $196 \pm 5$ & $116 \pm 6$ & $192 \pm 7$ & $147 \pm 6$ & $205 \pm 7$ & $186 \pm 5$ \\
$600{ }^{\circ} \mathrm{C}$ & $179 \pm 4$ & $103 \pm 6$ & $194 \pm 2$ & $137 \pm 4$ & $213 \pm 4$ & $183 \pm 3$ \\
\hline
\end{tabular}

Table 2 The Young's modulus of F82H from RT to $600{ }^{\circ} \mathrm{C}$ [30].

\begin{tabular}{ccccc}
\hline Young's modulus $(\mathrm{GPa})$ & $\mathrm{RT}$ & $300{ }^{\circ} \mathrm{C}$ & $500{ }^{\circ} \mathrm{C}$ & $600{ }^{\circ} \mathrm{C}$ \\
\hline $\mathrm{E}$ & 216 & 201 & 186 & 173 \\
\hline
\end{tabular}



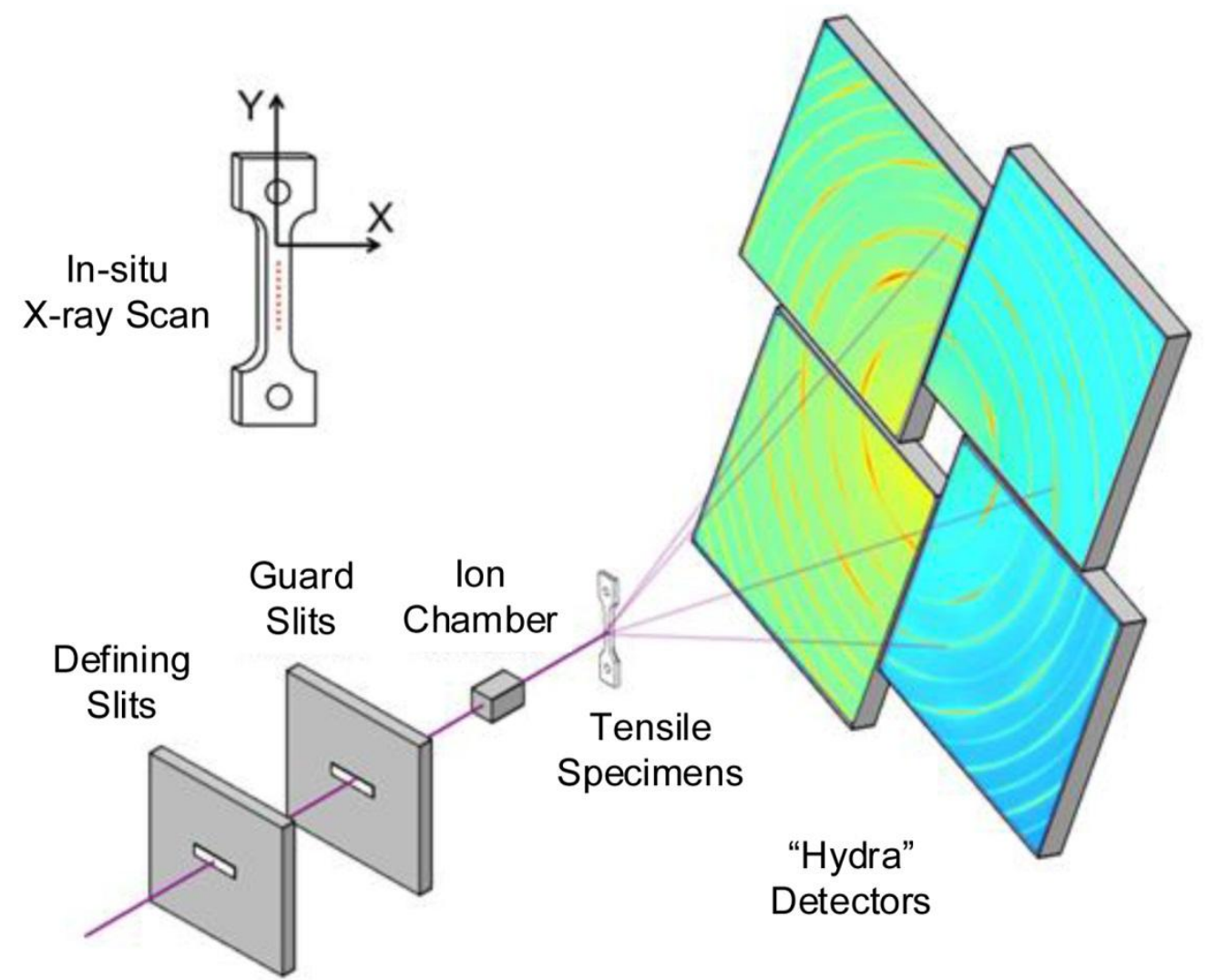

\section{0keV X-ray}

Figure 1: Experimental set-up of the tensile test with in-situ synchrotron X-ray diffraction. 


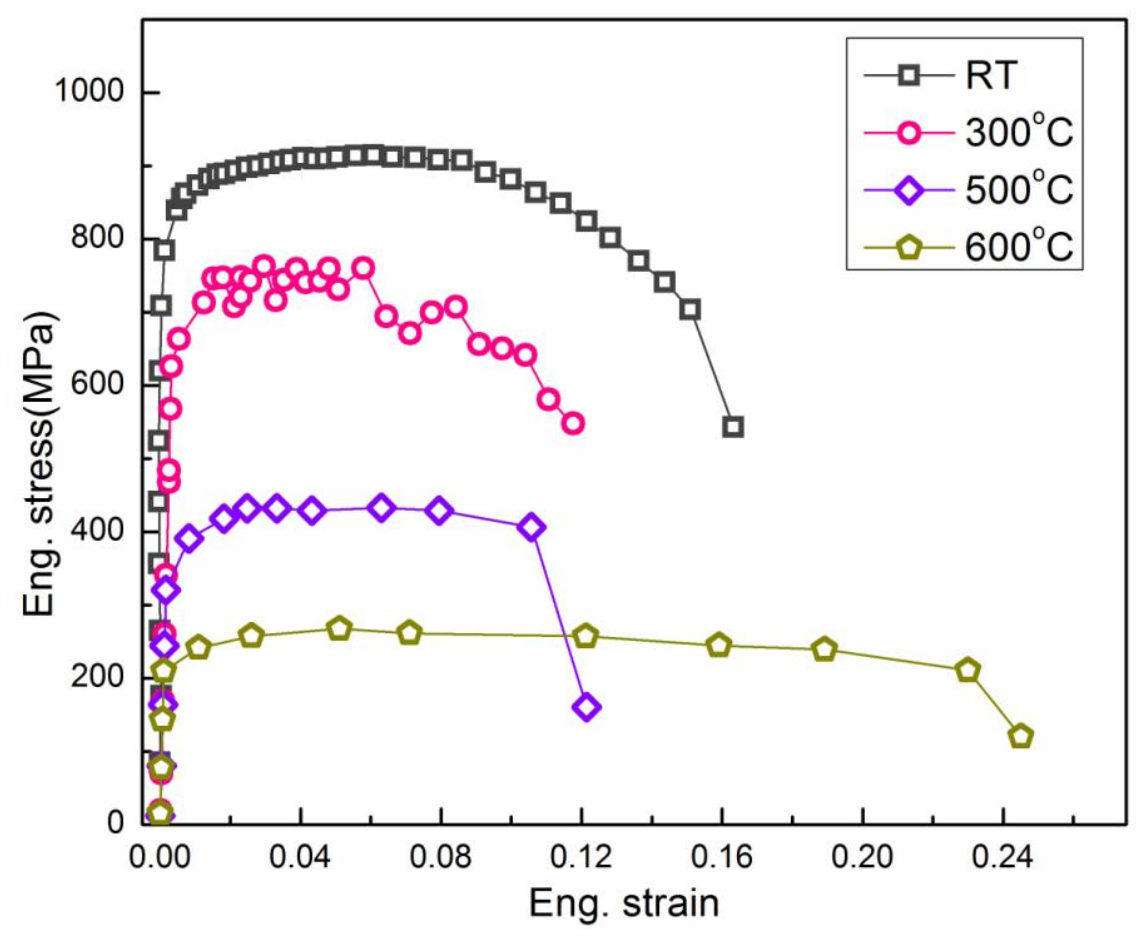

Figure 2: Engineering stress vs. engineering strain from RT to $600{ }^{\circ} \mathrm{C}$. 


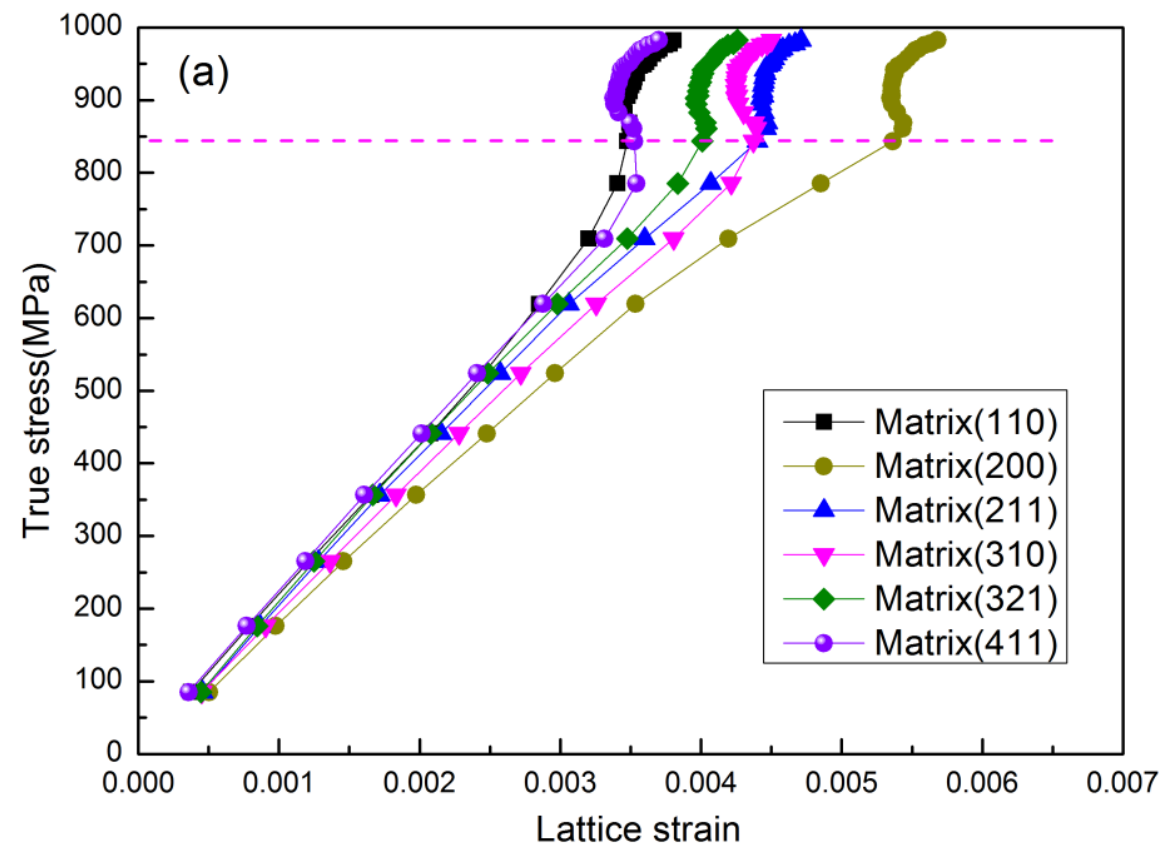

Figure (a)

Figure 3: The true stress vs. lattice strain for six different $\langle\mathrm{hkl}>/ /$ tensile direction families of grains for 9Cr F/M ODS steel at (a) RT; and (b) $600{ }^{\circ} \mathrm{C}$. 


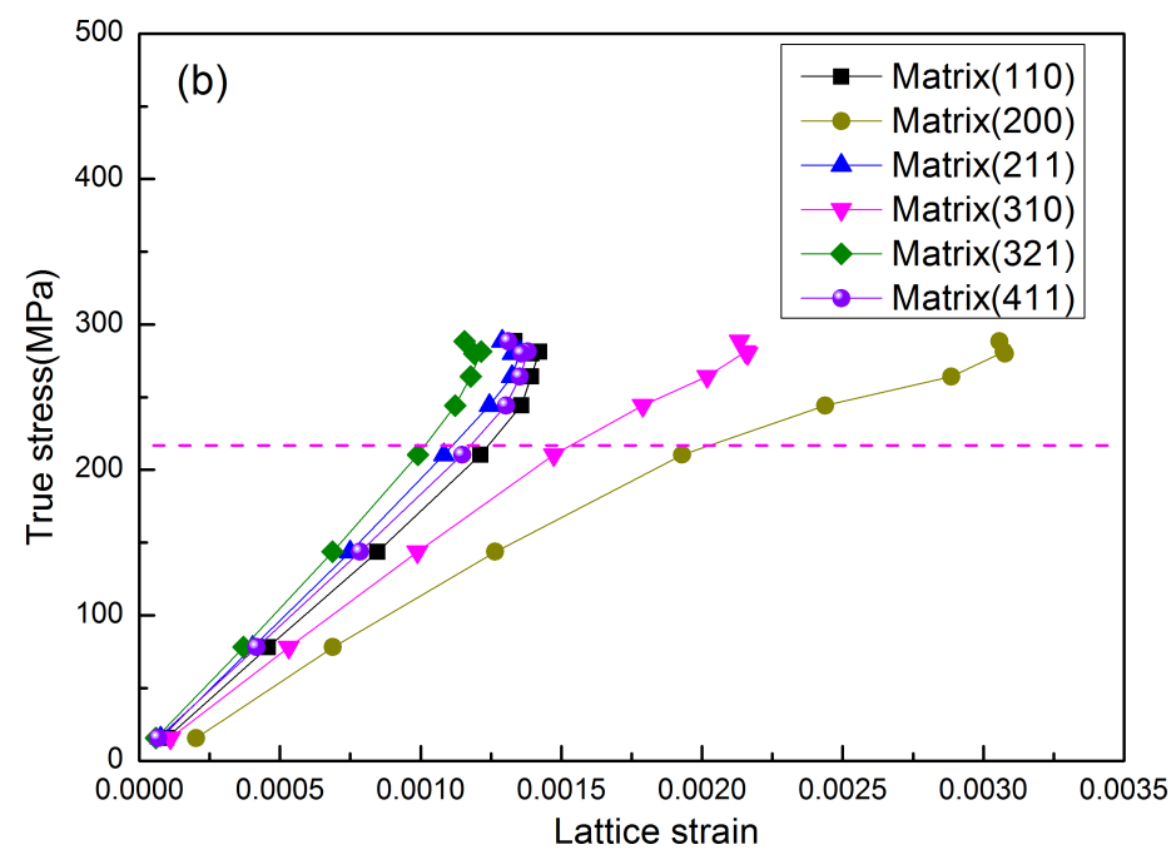

Figure (b)

Figure 3: The true stress vs. lattice strain for six different $<\mathrm{hkl}>/ /$ tensile direction families of grains for $9 \mathrm{Cr}$ F/M ODS steel at (a) RT; and (b) $600{ }^{\circ} \mathrm{C}$. 


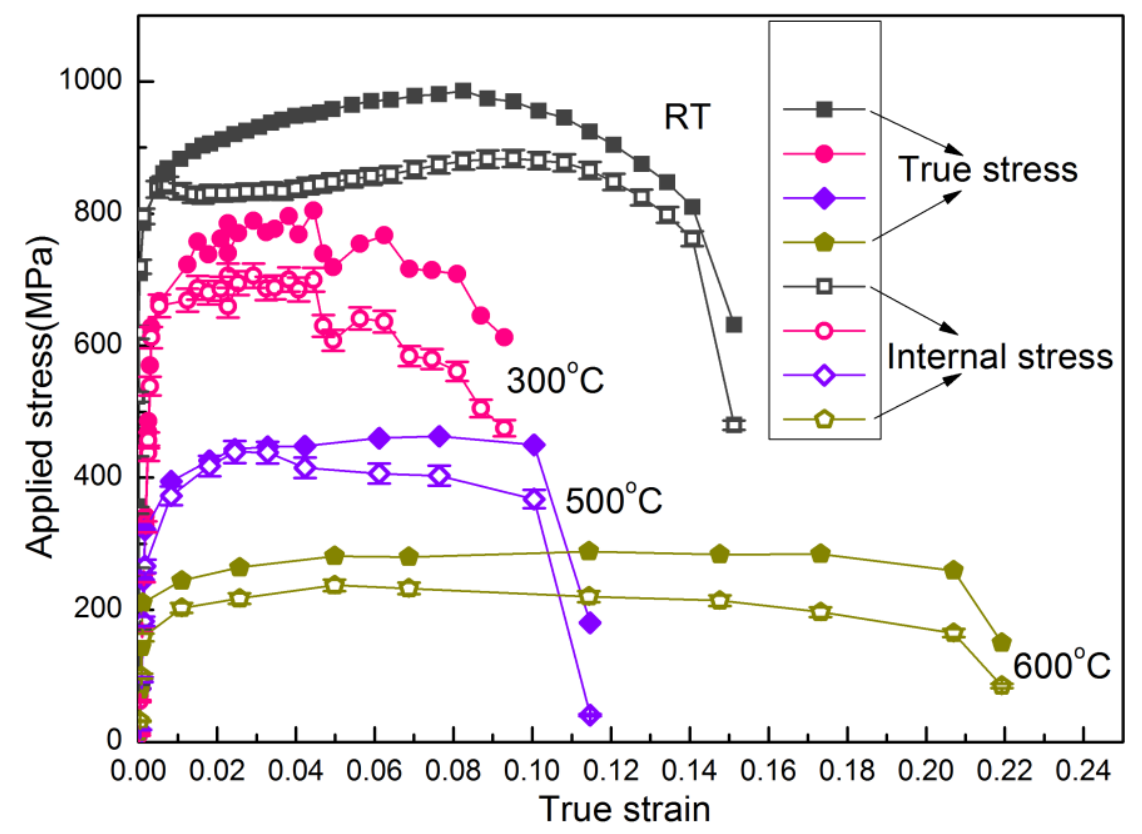

Figure 4: The true stress and mean internal stress of 9Cr F/M ODS steel during tensile test at RT, $300{ }^{\circ} \mathrm{C}, 500{ }^{\circ} \mathrm{C}, 600{ }^{\circ} \mathrm{C}$. 


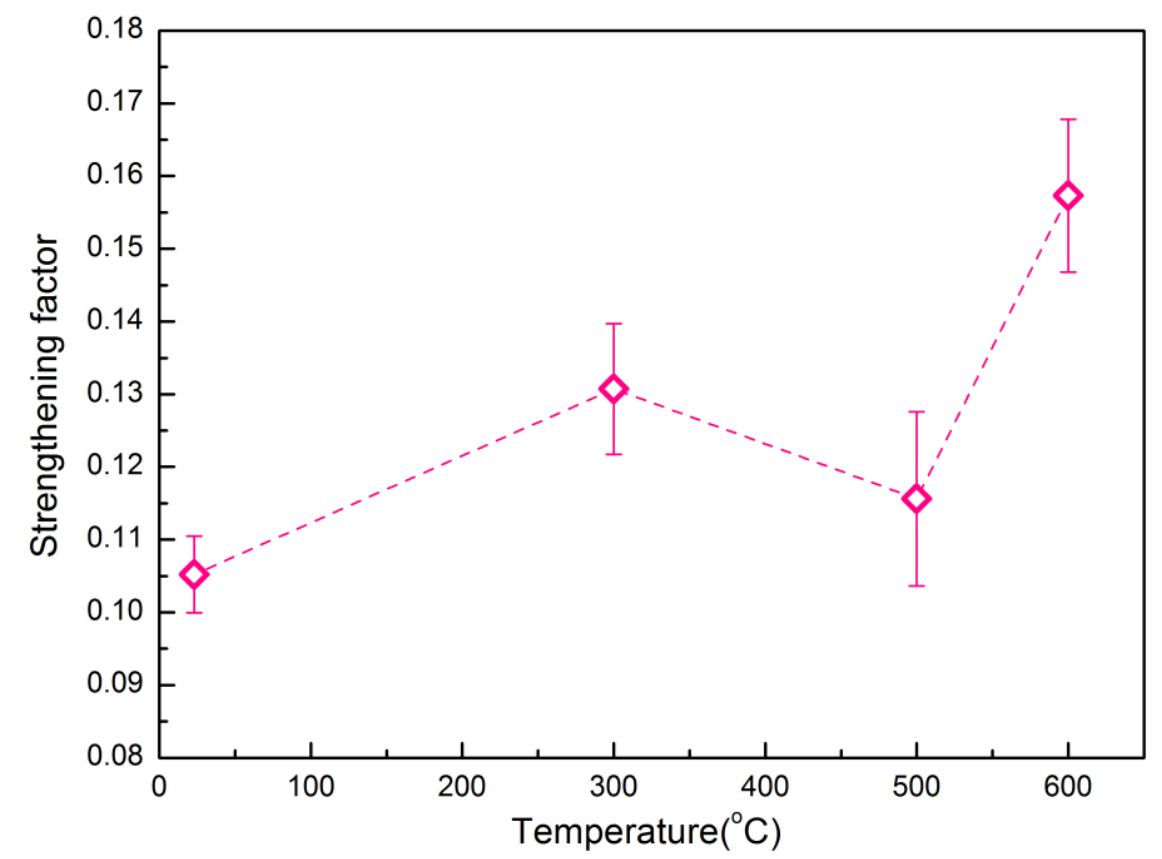

Figure 5: The strengthening factor of 9Cr F/M ODS steel 


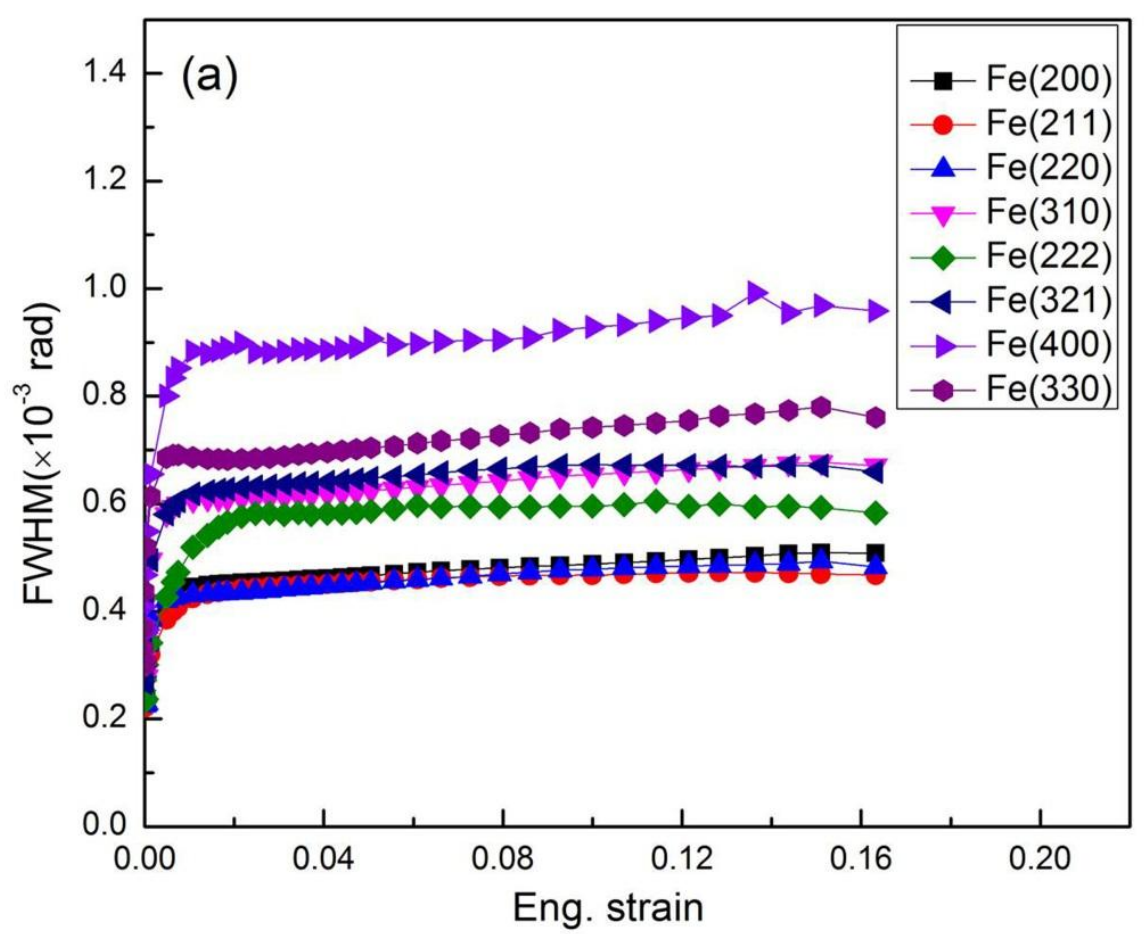

Figure (a)

Figure 6: Evolution of the FWHM of the Fe-Cr matrix as a function of strain during tensile deformation for $9 \mathrm{Cr}$ F/M ODS steel at (a) RT; and (b) $600{ }^{\circ} \mathrm{C}$. 


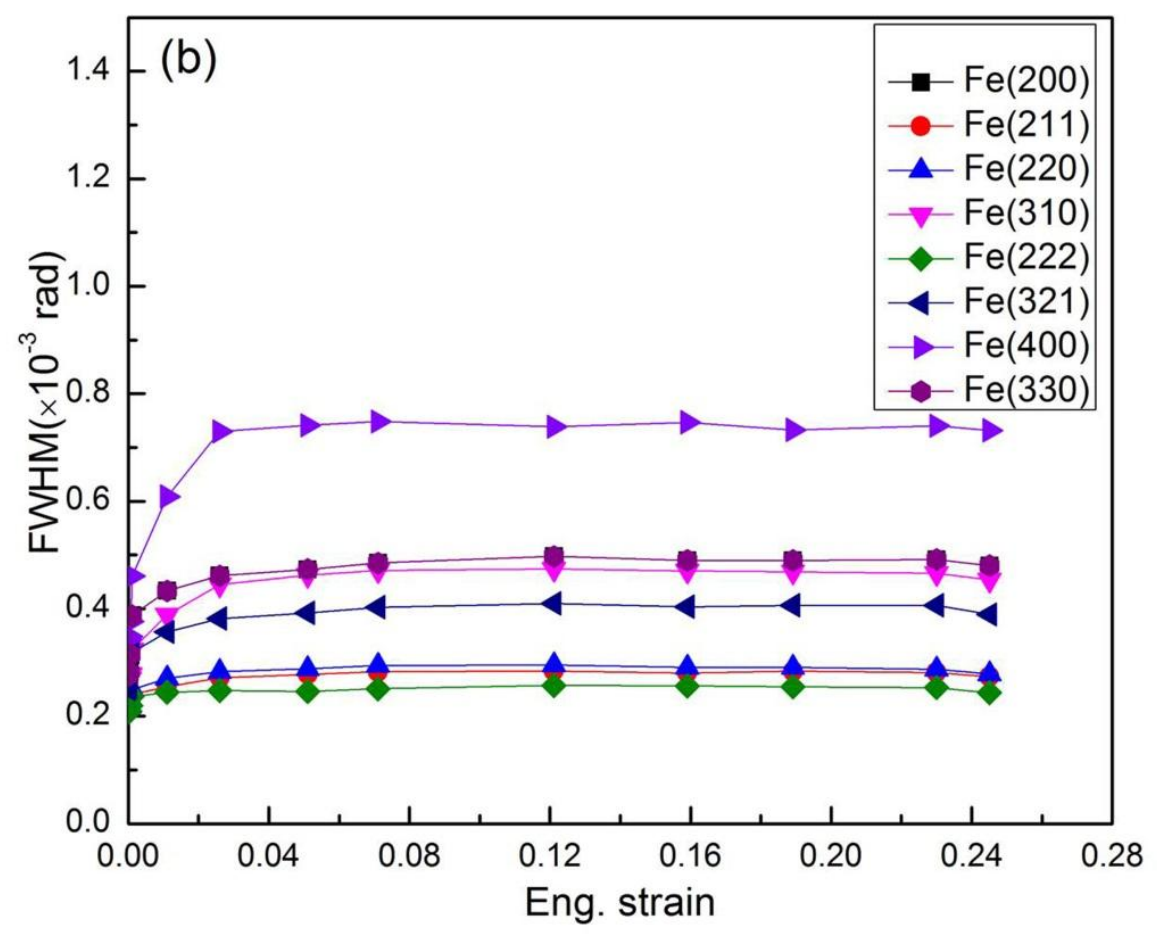

Figure (b)

Figure 6: Evolution of the FWHM of the $\mathrm{Fe}-\mathrm{Cr}$ matrix as a function of strain during tensile deformation for $9 \mathrm{Cr}$ F/M ODS steel at (a) RT; and (b) $600{ }^{\circ} \mathrm{C}$. 


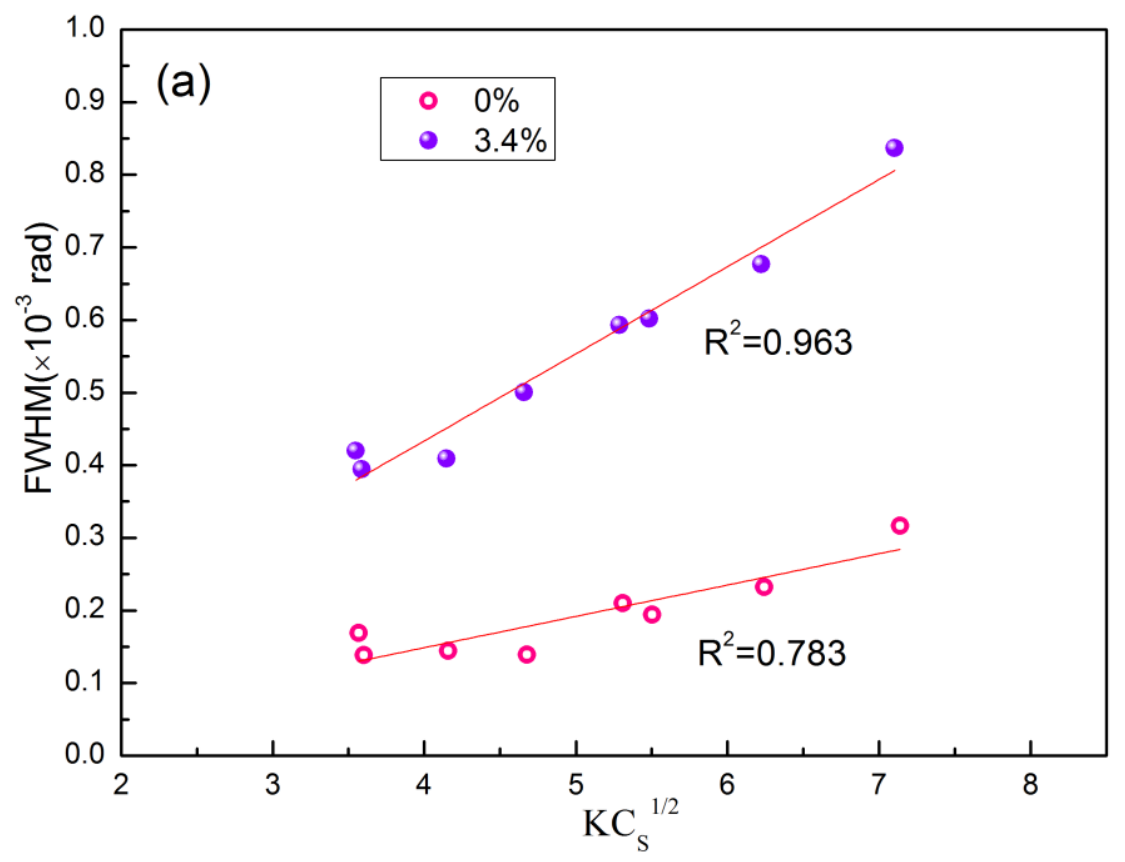

Figure (a)

Figure 7: The modified Williamson-Hall plots for Fe-Cr peaks at different strains at RT using the dislocation contrast factor of (a) pure edge type dislocations; (b) pure screw type dislocations; and (c) best-fit method 


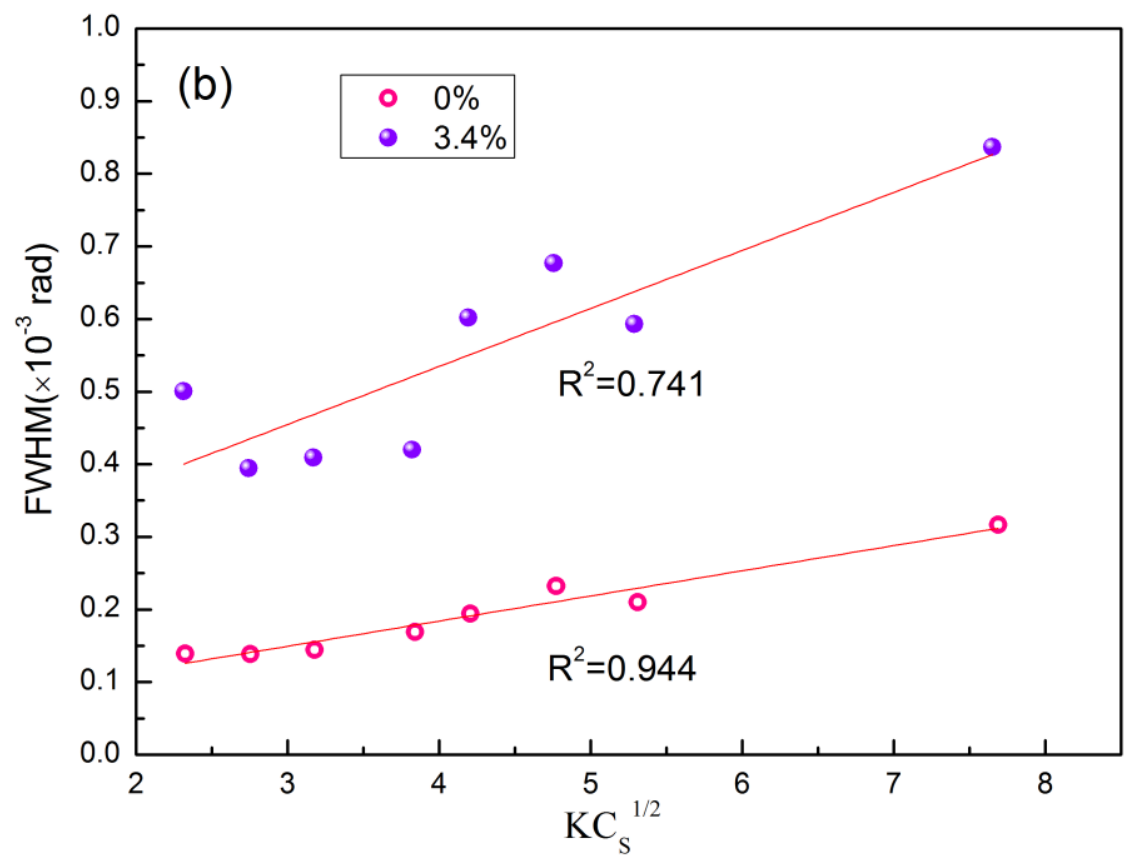

Figure (b)

Figure 7: The modified Williamson-Hall plots for Fe-Cr peaks at different strains at RT using the dislocation contrast factor of (a) pure edge type dislocations; (b) pure screw type dislocations; and (c) best-fit method 


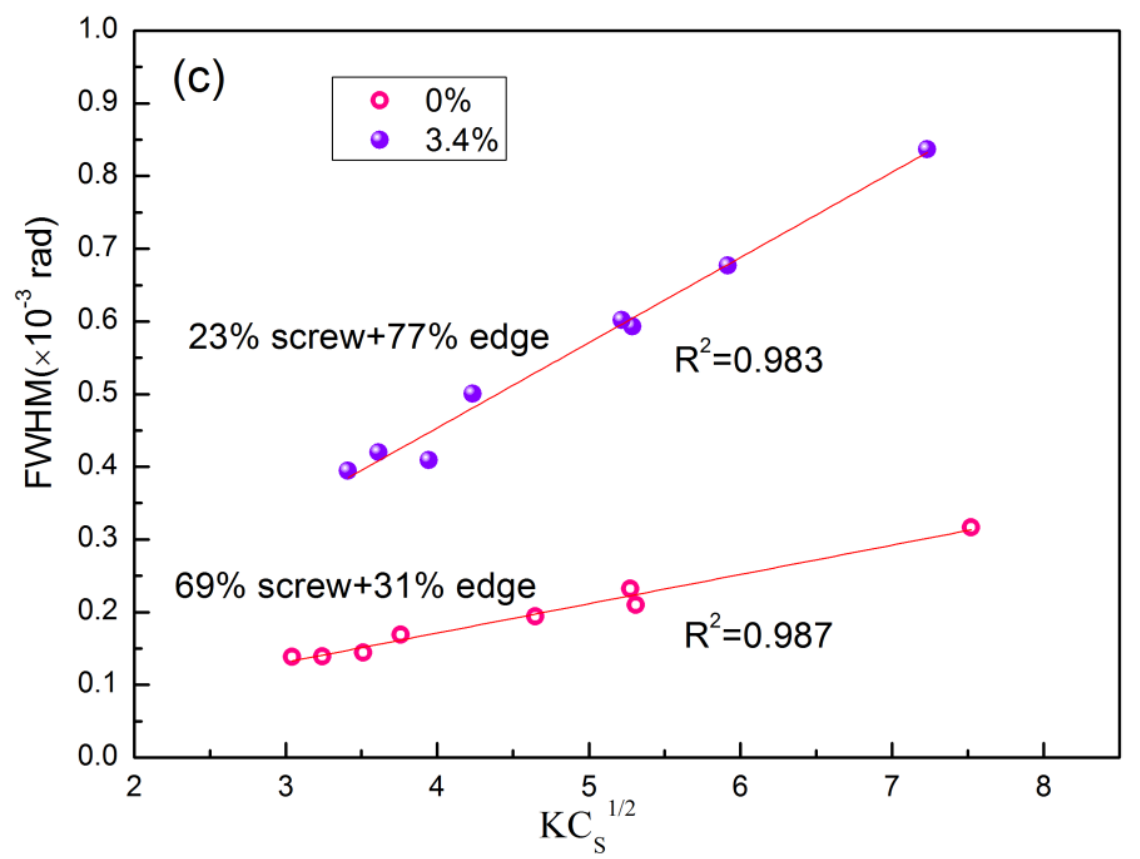

Figure (c)

Figure 7: The modified Williamson-Hall plots for Fe-Cr peaks at different strains at RT using the dislocation contrast factor of (a) pure edge type dislocations; (b) pure screw type dislocations; and (c) best-fit method 


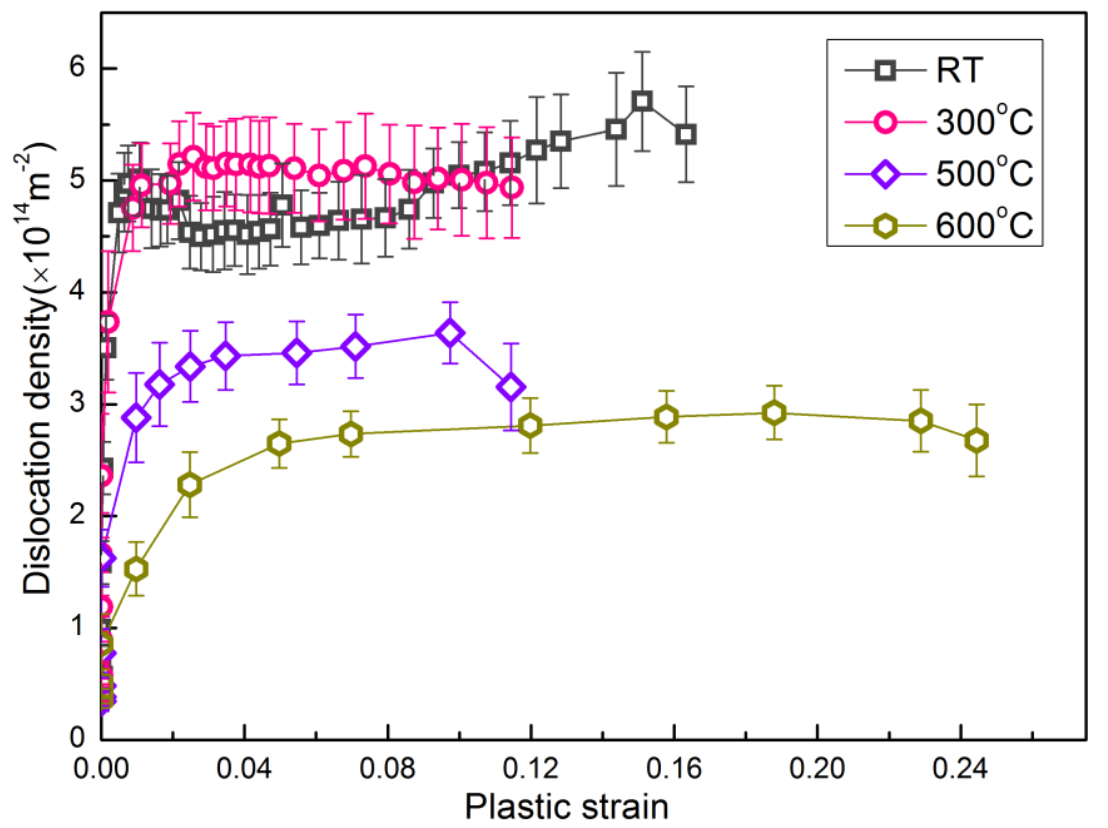

Figure 8: The evolution of dislocation density as a function of plastic strain for 9Cr F/M ODS steel at RT, $300{ }^{\circ} \mathrm{C}$, and $600{ }^{\circ} \mathrm{C}$. 


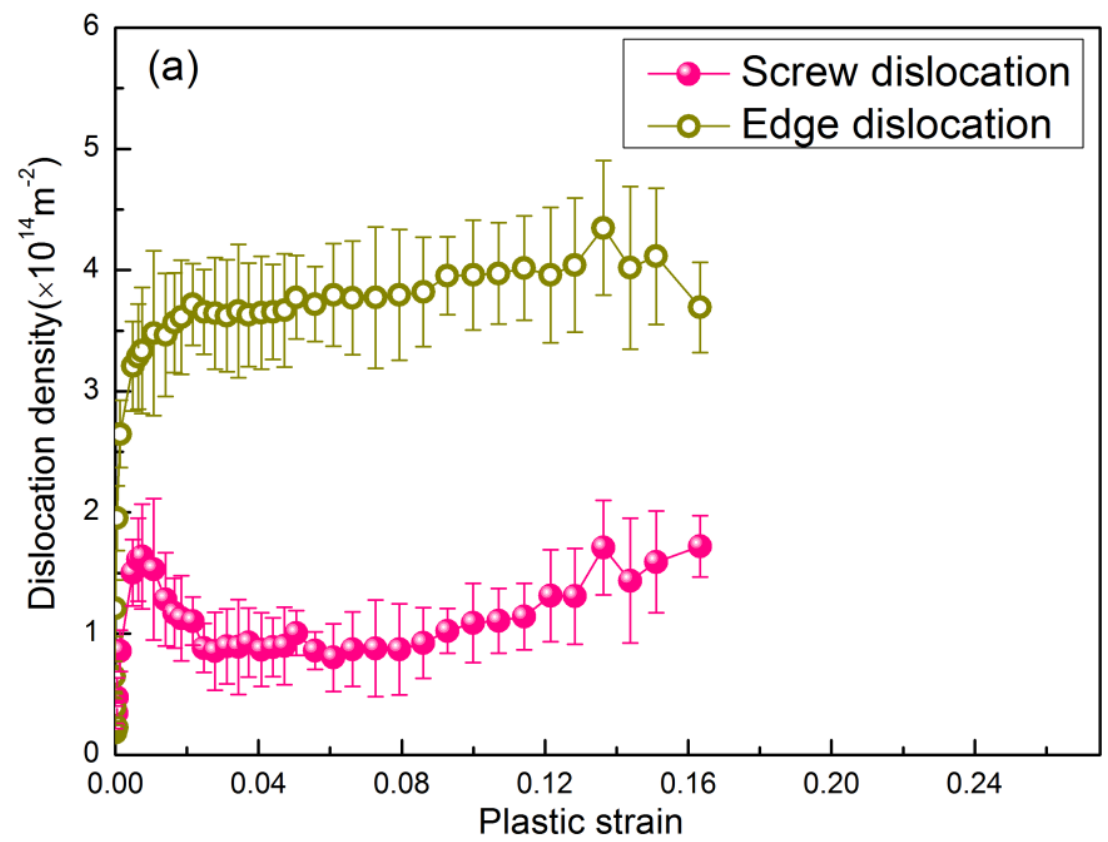

Figure (a)

Figure 9: The density evolution of edge type and screw type dislocations with increasing plastic strain of $9 \mathrm{Cr}$ F/M ODS steel at (a) RT; (b) $300{ }^{\circ} \mathrm{C}$; and (c) $600{ }^{\circ} \mathrm{C}$. 


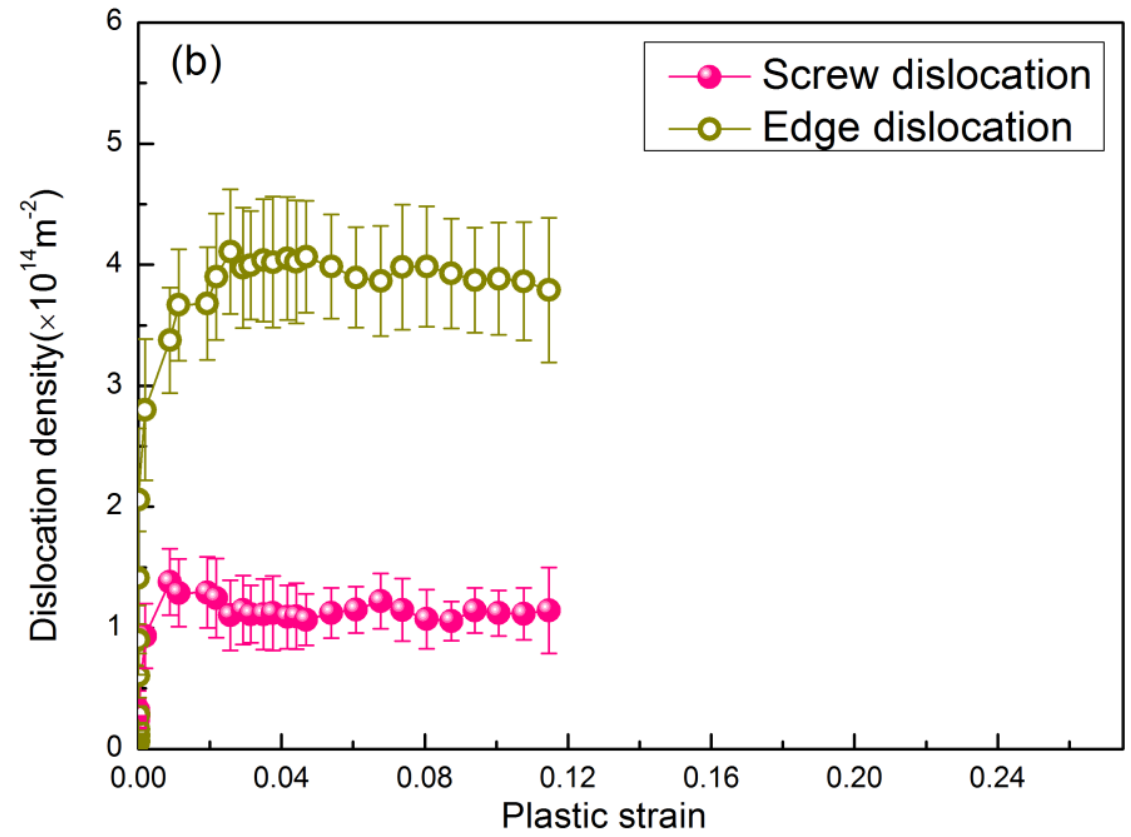

Figure (b)

Figure 9: The density evolution of edge type and screw type dislocations with increasing plastic strain of $9 \mathrm{Cr}$ F/M ODS steel at (a) RT; (b) $300{ }^{\circ} \mathrm{C}$; and (c) $600{ }^{\circ} \mathrm{C}$. 


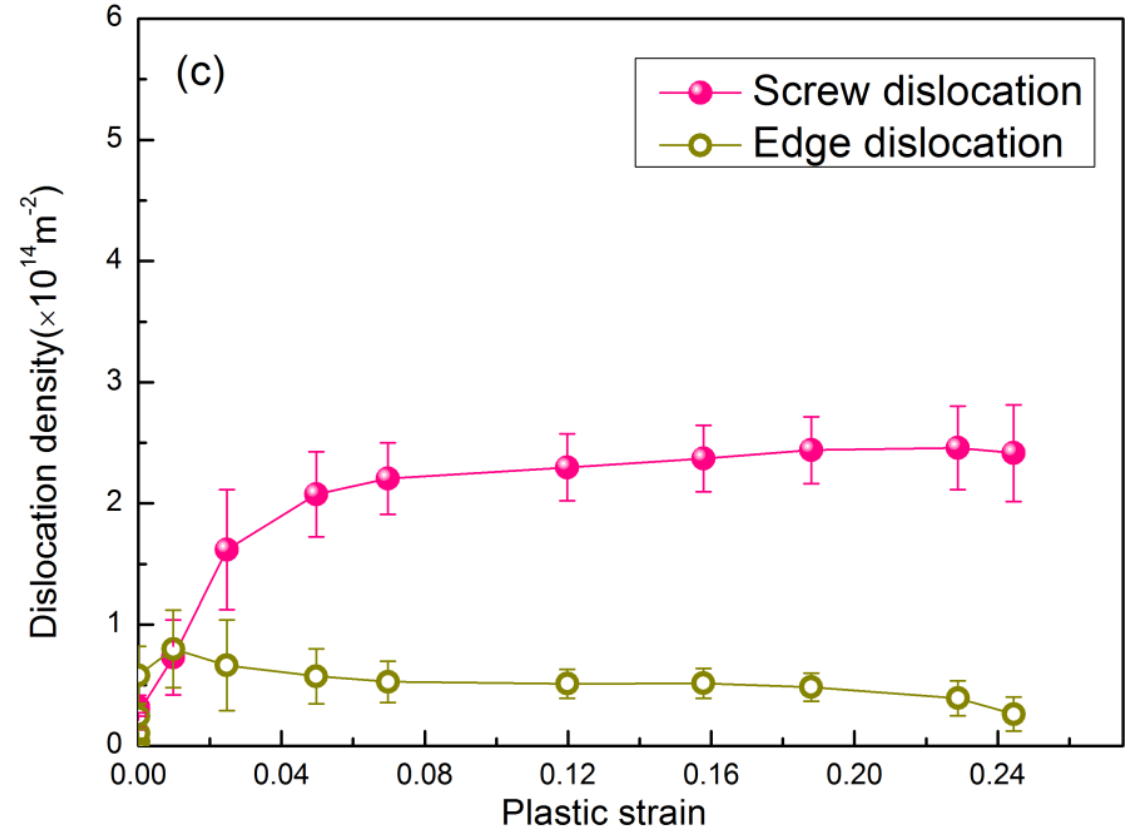

Figure (c)

Figure 9: The density evolution of edge type and screw type dislocations with increasing plastic strain of $9 \mathrm{Cr}$ F/M ODS steel at (a) RT; (b) $300{ }^{\circ} \mathrm{C}$; and (c) $600{ }^{\circ} \mathrm{C}$. 


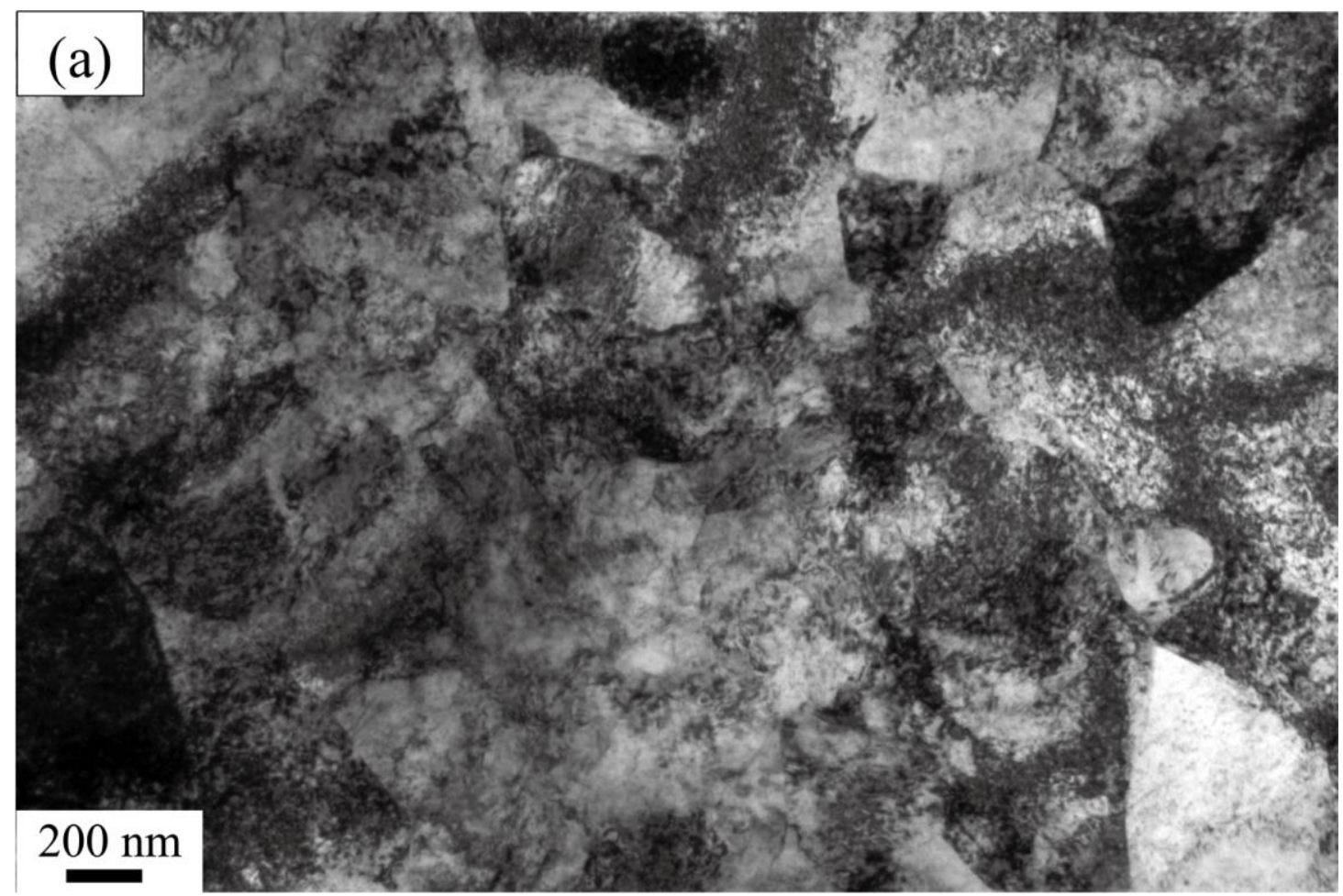

Figure (a)

Figure 10: The bright field of TEM images of post-tensile testing specimens of 9Cr F/M ODS steel at (a) RT; (b) $300{ }^{\circ} \mathrm{C}$; and (c) $600{ }^{\circ} \mathrm{C}$. 


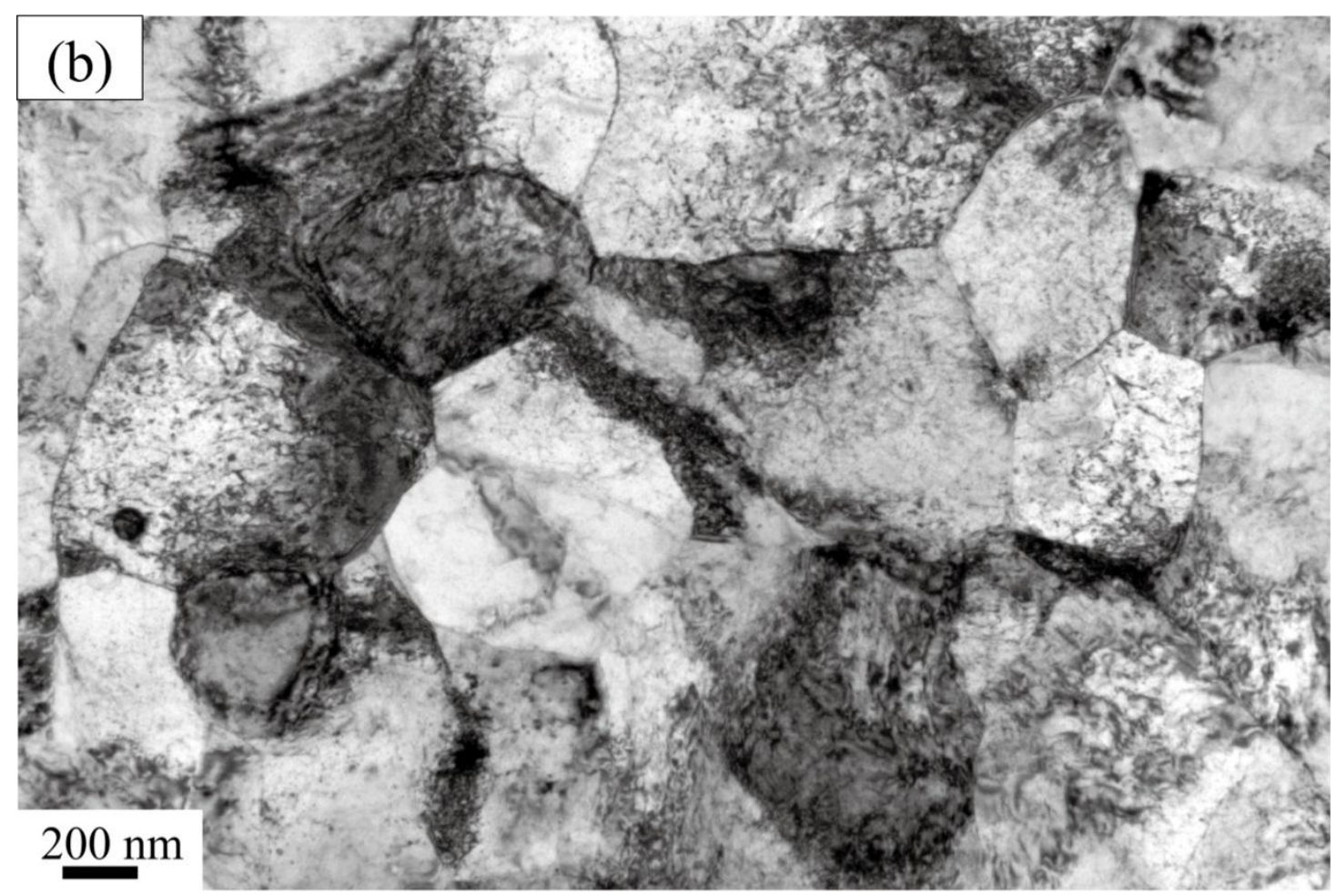

Figure (b)

Figure 10: The bright field of TEM images of post-tensile testing specimens of 9Cr F/M ODS steel at (a) RT; (b) $300{ }^{\circ} \mathrm{C}$; and (c) $600{ }^{\circ} \mathrm{C}$ 


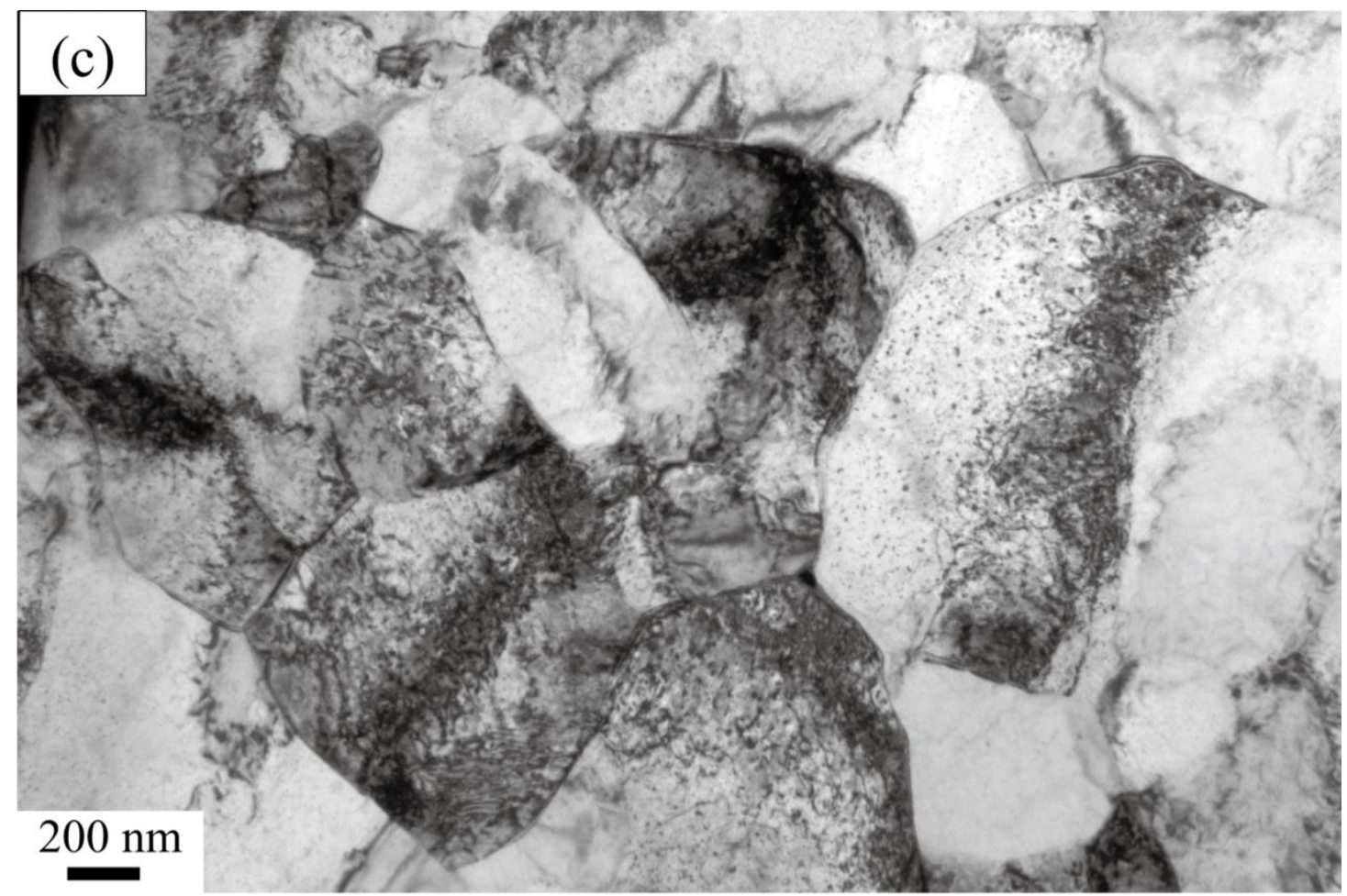

Figure (c)

Figure 10: The bright field of TEM images of post-tensile testing specimens of 9Cr F/M ODS steel at (a) RT; (b) $300{ }^{\circ} \mathrm{C}$; and (c) $600{ }^{\circ} \mathrm{C}$. 